\title{
BDNF Regulates the Translation of a Select Group of mRNAs by a Mammalian Target of Rapamycin-Phosphatidylinositol 3-Kinase-Dependent Pathway during Neuronal Development
}

\author{
Gerhard M. Schratt, ${ }^{1 *}$ Elizabeth A. Nigh, ${ }^{2 *}$ Wen G. Chen, ${ }^{3}$ Linda Hu, ${ }^{1}$ and Michael E. Greenberg ${ }^{1}$ \\ ${ }^{1}$ Departments of Neurology and Neurobiology, ${ }^{2}$ Program in Neuroscience, and ${ }^{3}$ Program in Biological and Biomedical Sciences, Harvard Medical School \\ and Division of Neuroscience, Children's Hospital, Boston, Massachusetts 02115
}

\begin{abstract}
Local regulation of mRNA translation plays an important role in axon guidance, synaptic development, and neuronal plasticity. Little is known, however, regarding the mechanisms that control translation in neurons, and only a few mRNAs have been identified that are locally translated within axon and dendrites. Using Affymetrix gene arrays to identify mRNAs that are newly associated with polysomes after exposure to BDNF, we identified subsets of mRNAs for which translation is enhanced in neurons at different developmental stages. In mature neurons, many of these mRNAs encode proteins that are known to function at synapses, including CamKII $\alpha$, NMDA receptor subunits, and the postsynaptic density (PSD) scaffolding protein Homer2. BDNF regulates the translation of Homer2 locally in the synaptodendritic compartment by activating translational initiation via a mammalian target of rapamycin-phosphatidylinositol 3-kinase-dependent pathway. These findings suggest that BDNF likely regulates synaptic function by inducing the local synthesis of numerous synaptic proteins. The local translation of the cytoskeleton-associated protein Homer2 in particular might have important implications for growth cone dynamics and dendritic spine development.
\end{abstract}

Key words: BDNF; translation; microarray; axon guidance; synaptic plasticity; rapamycin

\section{Introduction}

During nervous system development, the processes of axon guidance and synapse formation are dependent on new protein synthesis (Campbell and Holt, 2001; Zhang et al., 2001; Brittis et al., 2002; Ming et al., 2002). Moreover, higher brain functions that are related to synaptic plasticity, such as learning and memory, require new protein synthesis (Kang and Schuman, 1996; Kelleher et al., 2004). Although the bulk of mRNAs are translated in the neuronal cell body, local translation of specific mRNAs might be of particular importance for the regulation of protein expression within axons and dendrites. Multiple mRNAs, as well as components of the translational machinery, have been detected in dendrites and axon growth cones (Steward and Schuman, 2001), and extracellular stimulation regulates the translation of

\footnotetext{
Received May 6, 2004; revised July 7, 2004; accepted July 8, 2004.

This research was supported by a National Institutes of Health (NIH) Mental Retardation Center grant (P30HD18655) and an NIH grant (NS28829) to M.E.G. M.E.G. acknowledges the generous contribution of the F. M. Kirby Foundation to the Division of Neuroscience. G.M.S. is the recipient of a Long-Term Fellowship from the Human Frontier Science Program. We thank members of the Kosik laboratory for advice with polysome assays, M. Ericsson for electron microscopy, and K. H. Wang and G. Corfas for help with in situ hybridization. J. Lawrence kindly provided anti-4E-BP1 antibodies and the 4E-BP1 CDNA. The Homer2 antibody was a generous gift from P. Worley. We also thank members of the Greenberg laboratory for support and critical reading of this manuscript.

*G.M.S. and E.A.N. contributed equally to this work.

Correspondence should be addressed to Michael E. Greenberg, Departments of Neurology and Neurobiology, Harvard Medical School and Division of Neuroscience, Children's Hospital, Boston, MA 02115. E-mail: michael.greenberg@tch.harvard.edu.

W. G. Chen's present address: Division of Biological Engineering, Massachusetts Institute of Technology, Cambridge, MA 02139.

DOI:10.1523/JNEUROSCI.1739-04.2004

Copyright $\odot 2004$ Society for Neuroscience $\quad$ 0270-6474/04/247366-12\$15.00/0
}

these mRNAs (Steward et al., 1998; Wu et al., 1998; Ouyang et al., 1999; Scheetz et al., 2000; Aakalu et al., 2001).

In non-neuronal cells, extracellular factors such as insulin-like growth factor I (IGF-I) can regulate the level of translation of a subset of cellular mRNAs by modifying specific components of the translation machinery and thus affecting their activity. For example, phosphorylation of eukaryotic initiation factor $4 \mathrm{E}$ (eIF$4 \mathrm{E}$ ) in response to IGF-I treatment increases the affinity of eIF- $4 \mathrm{E}$ for the 7-methyl-G(5')ppp $\left(5^{\prime}\right) \mathrm{N}$ cap, thereby stimulating capdependent translation (Raught and Gingras, 1999). Growth factor-induced phosphorylation of eIF-4E binding proteins (4EBPs) blocks the ability of these proteins to bind eIF-4E, further promoting the translation of cellular mRNAs (Gingras et al., 2001). Similarly, the growth factor-induced phosphorylation of ribosomal subunit $\mathrm{S} 6$ by the $\mathrm{p} 70 \mathrm{~S} 6$ kinase $\left(\mathrm{p} 70^{\mathrm{S} 6 \mathrm{~K}}\right)$ correlates with the induced translation of a subset of cellular mRNAs (van der Velden and Thomas, 1999).

BDNF regulates a wide range of cellular responses in the nervous system, including dendritic and axonal growth (CohenCory and Fraser, 1995; McAllister et al., 1995), neuronal survival, synaptic transmission, and long-term potentiation in the hippocampus (Korte et al., 1995; Schuman, 1999). Several recent studies have suggested that BDNF regulates neuronal function in part through the local control of protein synthesis (Kang and Schuman, 1996; Huber et al., 2000; Zhang and Poo, 2002). Little is known, however, regarding the molecular mechanisms by which BDNF affects mRNA translation, and only a few mRNAs (e.g., CamKII $\alpha$, Arc) whose translation is induced by BDNF have been identified (Aakalu et al., 2001; Yin et al., 2002). 
In this study, we performed a genome-wide screen for mRNAs whose translation is regulated in neurons by BDNF via the mammalian target of rapamycin (mTOR) signaling pathway. We identified specific subsets of mRNAs whose association with polysomes is induced by BDNF in immature [ $4 \mathrm{~d}$ in vitro (DIV)] or mature (14 DIV) neurons. Many of the BDNF-regulated mRNAs in mature neurons encode proteins that function at synapses, supporting the possibility that BDNF-induced translation of specific mRNAs is relevant for synaptic function. Focusing on one of these mRNAs, we show that Homer2 is localized in dendrites and locally translated at synapses in response to BDNF. The further characterization of these BDNF-regulated mRNAs should enhance our understanding of how BDNF regulates axonal and dendritic function.

\section{Materials and Methods}

Cell culture and reagents. Cortical and hippocampal neurons from embryonic day 18 (E18) Long-Evans rats (Charles River Laboratories, Wilmington, MA) were isolated as described previously (Xia et al., 1996). Cortical neurons were maintained in Basal Medium Eagle (BME) (Invitrogen, Gaithersburg, MD) containing 5\% fetal bovine serum, penicillin-streptomycin ( $50 \mu \mathrm{g} / \mathrm{ml}$ penicillin, $50 \mathrm{U} / \mathrm{ml}$ streptomycin; Sigma, St. Louis, MO), and glutamine ( $1 \mathrm{~mm}$; Sigma). Hippocampal neurons were maintained in Neurobasal Medium plus B27 supplement (Invitrogen). Unless indicated otherwise, neurons were incubated in serum-free BME for $2 \mathrm{hr}$ and pretreated with $1 \mu \mathrm{g} / \mathrm{ml}$ actinomycin D (Calbiochem, La Jolla, CA) for $40 \mathrm{~min}$ before each experiment. Cultures were stimulated with $50 \mathrm{ng} / \mathrm{ml}$ BDNF, IGF-I, or NGF, or $60 \mathrm{~mm} \mathrm{KCl}$ for indicated times. Ephrin stimulation was performed as described previously (Shamah et al., 2001). When appropriate, $20 \mathrm{ng} / \mathrm{ml}$ rapamycin (Calbiochem), $25 \mu \mathrm{M}$ LY294002 (Calbiochem), and $60 \mu \mathrm{M}$ PD98059 were added 30-60 min before stimulation as indicated.

Polysome assays. Cultured neurons $\left(2 \times 10^{7}\right)$ were washed twice in ice-cold PBS containing $3 \mu \mathrm{g} / \mathrm{ml}$ cycloheximide. Cultures were collected on ice in $375 \mu$ l of LSB buffer (20 mM Tris, pH 7.5, $10 \mathrm{~mm} \mathrm{NaCl}, 30 \mathrm{~mm}$ $\mathrm{MgCl}_{2}$ ) supplemented with $6.6 \mathrm{~mm}$ DTT and $1 \mathrm{U} / \mu \mathrm{l}$ human placental RNase inhibitor (Amersham Biosciences, Arlington Heights, IL) and then lysed by addition of $125 \mu$ l of lysis buffer A (LSB, $0.2 \%$ Triton X-100, $0.2 \mathrm{M}$ sucrose). Samples were centrifuged at $10,000 \times g$ for $5 \mathrm{~min}$, and the supernatant was adjusted to $150 \mathrm{mM} \mathrm{NaCl}, 10 \mathrm{mM} \mathrm{MgCl}_{2}$ and layered onto a $15-45 \%$ linear sucrose gradient containing $5 \mathrm{U} / \mathrm{ml}$ SUPERASEin (Ambion, Austin, TX). Sucrose solutions were prepared using $25 \mathrm{~mm}$ Tris, pH 7.5, $25 \mathrm{~mm} \mathrm{NaCl}, 5 \mathrm{~mm} \mathrm{MgCl}_{2}$ in RNase-free water. Samples were centrifuged at $40,000 \times g$ for 78 min and fractionated through a continuous-flow UV absorbance detector (ISCO, Lincoln, NE, and Brandel, Gaithersburg, MD) into Eppendorf tubes containing SDS at a final concentration of $1 \%$. UV absorbance was collected digitally using an NIDAQ PCMCIA card (National Instruments) and an IgorPro interface (Wavemetrics). Polysome/free subunit (P/F) ratios were determined by dividing the integral of the curve representing polysome-bound mRNA by that of the free $80 \mathrm{~S}$ ribosome. Although this ratio does not represent a direct measure of the number of mRNAs moving into the polysome fraction, it is a numerical representation of the changing distribution of messenger and ribosomal RNA throughout the gradient.

Microarray analysis. For each array, RNA was purified from the combined polysome-containing fractions (see Fig. $4 A$, fractions 5 and 6) from two polysome preparations. Gradient fractions collected in 1\% SDS were precipitated in $1 \mathrm{vol}$ of isopropanol for $48 \mathrm{hr}$ at $-20^{\circ} \mathrm{C}$. After centrifugation, the pellets were resuspended and repurified with an Absolutely RNA RT-PCR Miniprep Kit (Stratagene, La Jolla, CA). Five micrograms of total RNA were used for double-stranded cDNA synthesis and subsequent in vitro transcription (IVT). After purification of the IVT reaction, biotin-labeled cRNA was hybridized to Affymetrix rat microarrays (Rat genome U34A) containing 8800 genes, per manufacturer's instructions. Arrays from polysome fractions of unstimulated $(n=3)$, BDNF-treated $(n=3)$, and BDNF-treated neurons in the presence of rapamycin $(n=2)$ were analyzed. A lower threshold of 20 was used for raw expression values, and fold inductions were calculated by dividing values from BDNF-treated arrays by values from unstimulated arrays. Targets were scored as positive if the average signal from all three BDNFtreated arrays increased by at least 30\% (fold induction $=1.3$ ) over the unstimulated arrays and the signal did not increase in the two rapamycin-treated arrays (fold induction $<1$ ).

Quantitative real-time PCR. cDNA was prepared from $1 \mu \mathrm{g}$ of purified RNA from either polysome fractions (combined fractions 5 and 6) or total cellular extracts using the First Strand SuperScript II kit (Invitrogen). PCR was performed in a TaqMan (PerkinElmer Life Sciences, Emeryville, CA) using an SYBR-green-containing PCR kit (PE Applied Biosystems, Foster City, CA). Each independent sample was analyzed in quadruplicate from RNA collected from at least three independent polysome assays. The threshold cycle for each sample was chosen in the linear range and converted into a starting quantity by normalizing to the internal standard glyceraldehyde-3-phosphate dehydrogenase (GAPDH) run on the same plate for each set of primers. Single PCR products were verified in each well by observing a single peak in the $-\mathrm{df}$ (fluorescence)/dT (temperature) plot of the melting curve. (Primer sequences are available upon request.)

Western blot analysis. Neurons were harvested in boiling SDS buffer, resolved by SDS-PAGE, transferred to nitrocellulose membranes, and immunoblotted. Blots were incubated with primary antibodies, washed, and exposed to horseradish peroxidase-conjugated secondary antibodies. Peroxidase activity was visualized by enhanced chemiluminescence according to manufacturer's instructions. Anti-pan-tyrosine kinase receptor (Trk) antibodies were the generous gift from R. Segal (DanaFarber Cancer Institute, Boston, MA). Anti-phospho-Trk (Tyr490), anti-eIF4E, anti-phospho-eIF4E (Ser209), anti-p70 ${ }^{\mathrm{S} 6 \mathrm{~K}}$, and antiphospho-p70 ${ }^{\mathrm{S} 6 \mathrm{~K}}(\mathrm{Thr} 389)$ antibodies were purchased from Cell Signaling Technologies.

Preparation of synaptoneurosomes and radio-immunoprecipitation. Synaptoneurosomes from P15 Long-Evans rat pups (Charles River Laboratories) were prepared according to a previously published protocol (Rao and Steward, 1991). Briefly, total forebrains were dissected in $50 \mathrm{ml}$ of homogenization buffer ( $0.32 \mathrm{~m}$ sucrose, $0.1 \mathrm{~mm}$ EDTA, $0.25 \mathrm{~mm}$ DTT, 2 mm HEPES, pH 7.4) and disrupted with a Teflon-coated DouncePotter homogenizer (Wheaton) by eight up-and-down strokes. Nuclei and cell debris were pelleted by a $2 \mathrm{~min}$ centrifugation at $2000 \times g$. The supernatant was centrifuged for an additional $10 \mathrm{~min}$ at $14,000 \times \mathrm{g}$ to pellet a crude synaptoneurosome-containing fraction (P2). The $\mathrm{P} 2 \mathrm{frac}-$ tion was subsequently layered over a $5-13 \%$ discontinuous Ficoll gradient that had been equilibrated at $4^{\circ} \mathrm{C}$ for $1 \mathrm{hr}$. Synaptoneurosomes were collected from the gradient interface, washed once in PBS, and resuspended in synaptoneurosome incubation buffer ( $10 \mathrm{~mm}$ Tris, $\mathrm{pH} 7.5,2.2$ $\mathrm{mm} \mathrm{CaCl}_{2}, 0.5 \mathrm{~mm} \mathrm{Na}_{2} \mathrm{HPO}_{4}, 0.4 \mathrm{~mm} \mathrm{KH}_{2} \mathrm{PO}_{4}, 4 \mathrm{~mm} \mathrm{NaHCO}$, and 80 $\mathrm{mm} \mathrm{NaCl})$ to yield a final concentration of $1 \mathrm{mg} / \mathrm{ml}$. This fraction $(400$ $\mu \mathrm{l})$ was preincubated at $37^{\circ} \mathrm{C}$ for $10 \mathrm{~min}$ and stimulated with BDNF (50 $\mathrm{ng} / \mathrm{ml})$ in the presence or absence of rapamycin $(20 \mathrm{pg} / \mathrm{ml})$ for $60 \mathrm{~min}$. The stimulation was performed in the presence of $100 \mu \mathrm{Ci} / \mathrm{ml}\left[{ }^{35} \mathrm{~S}\right] \mathrm{me}$ thionine. Synaptoneurosomes were pelleted, washed in PBS, and resuspended in a modified RIPA buffer (1\%Triton X-100, 0.2\% SDS). After centrifugation at $14,000 \times g$ for $10 \mathrm{~min}$, the supernatant was incubated for $16 \mathrm{hr}$ with 3-5 $\mu \mathrm{g}$ of the indicated antibodies together with protein A Sepharose beads (Sigma). Beads were washed twice in RIPA buffer containing 1\% Triton X-100 and twice in RIPA buffer without detergent. Samples were eluted in boiling SDS sample buffer and resolved by SDSPAGE. Gels were fixed and dried, exposed overnight, and analyzed by densitometry (IPLabGel). Integrin $\alpha-1$ (FB12) antibodies were purchased from Chemicon International (Temecula, CA). GluR1 antibodies were obtained from Chemicon. The Homer2 antibody was a gift from P. Worley (Johns Hopkins University, Baltimore, MD).

Immunocytochemistry. Cortical neurons (7 DIV) were starved for $4 \mathrm{hr}$ in BME media lacking FBS, before being stimulated with BDNF for 10 min. Cells were fixed for $10 \mathrm{~min}$ in $4 \%$ paraformaldehyde, permeabilized with $0.2 \%$ Triton X-100 for 5 min, and blocked in BSA/NGS. Neurons were stained with monoclonal anti-phospho p70 ${ }^{\mathrm{S} 6 \mathrm{~K}}$ (Cell Signaling Technologies), anti-MAP2 (Chemicon), anti-PSD-95 (Affinity BioReagents, Golden, CO), anti-synapsin (Chemicon), and antibodies de- 
a

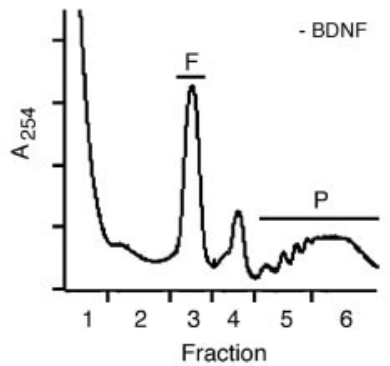

b

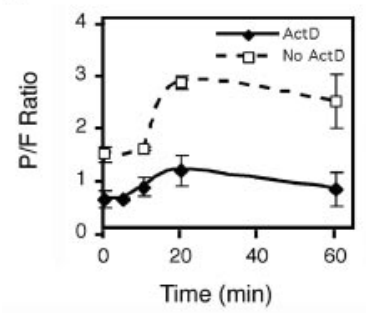

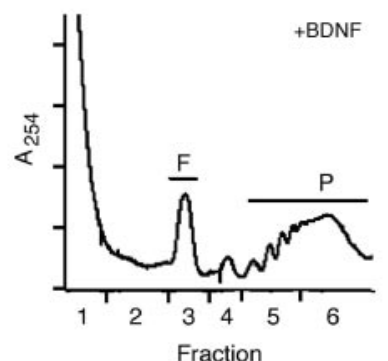

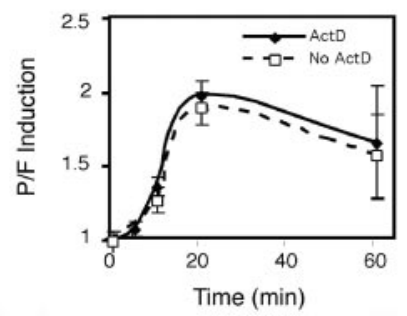

Figure 1. BDNF treatment increases protein translation in neurons. $a$, Effect of BDNF treatment on polysome profile. E18 rat cortical neurons at 4 DIV were treated with or without BDNF for $20 \mathrm{~min}$ and harvested. Lysates were applied to a 15-45\% linear sucrose gradient, centrifuged, and fractionated with continuous optical density measurement. F, Free ribosomal subunit fractions; $P$, polysome fractions. $b$, Time course of the polysome shift after BDNF treatment. After 2 hr serum starvation, neurons were treated with or without actinomycin D (ActD) for 40 min before BDNF treatment. The normalized ratio of the integral of the $F$ and $P$ curves was plotted as a function of time of BDNF stimulation. $P / F$ induction represents the relative change in $\mathrm{P} / \mathrm{F}$ ratio in stimulated cells to that of untreated neurons. Error bars represent the SE of at least five independent experiments.

scribed for Western analysis for $1 \mathrm{hr}$ at room temperature. Secondary Alexa goat anti-mouse (Molecular Probes, Eugene, OR; 1:500) and Cy3 goat anti-rabbit (1:250; Jackson ImmunoResearch, West Grove, PA) were applied for $1 \mathrm{hr}$ at room temperature. Coverslips were mounted with Aqua-Mount (Lerner \#13800). Image acquisition was done on a Nikon Eclipse E600 microscope using Spot software (Diagnostics). Pictures from control- and BDNF-treated cultures were taken at the same exposure time.

In situ hybridization. Hippocampal neurons (7 DIV) were fixed in $4 \%$ paraformaldehyde/DEPC-PBS for 15 min, treated with $0.25 \%$ acetic anhydride in $0.1 \mathrm{~m}$ TEA for $10 \mathrm{~min}$, and washed in PBS. Hybridization with digoxigenin (DIG)-labeled probes $(500 \mathrm{ng} / \mathrm{ml})$ was performed in hybridization buffer (50\% formamide, $10 \mathrm{~mm}$ Tris- $\mathrm{HCl}, \mathrm{pH} 8,200 \mu \mathrm{g} / \mathrm{ml}$ tRNA, $1 \times$ Denhardt's solution, $600 \mathrm{~mm} \mathrm{NaCl}, 0.25 \%$ SDS, 1 mm EDTA, $10 \%$ dextran sulfate) for $16 \mathrm{hr}$. Coverslips were washed twice with $2 \times$ SSC for $30 \mathrm{~min}$ at $60^{\circ} \mathrm{C}$, incubated with $12.5 \mathrm{mg} / \mathrm{ml}$ RNase $\mathrm{A}$ at $37^{\circ} \mathrm{C}$ for $30 \mathrm{~min}$, and washed twice with $0.2 \times$ SSC at $60^{\circ} \mathrm{C}$ for $30 \mathrm{~min}$. After blocking in TNB (DuPont NEN, Boston, MA) for $30 \mathrm{~min}$ at room temperature, fluorescein-conjugated anti-DIG antibody (Roche, Hertfordshire, UK; 1:200) was applied for $1 \mathrm{hr}$ at room temperature together with mouse anti-MAP2. The signal was amplified with Texas Red-conjugated antifluorescein antibody (Molecular Probes; 1:200) in the presence of secondary Alexa goat anti-mouse before mounting of coverslips in Aquamount. Image acquisition was done on a Nikon Eclipse E600 microscope using Spot software (Diagnostics), using the same exposure time for each of the target RNAs investigated. DIG-labeled sense probes were used for hybridization to confirm the specificity of the in situ hybridization protocol.

Statistical analysis was performed with NIH Image software. Dendrites were chosen in a blinded manner based on MAP2 staining, and average pixel intensities were derived along the entire dendrite (width $=4$ pixels). Background intensity was subtracted from each dendrite. To get an average intensity, dendrites were grouped into $10 \mu \mathrm{m}$ (=62 pixels) compartments, and the average pixel intensity was calculated for a total of $12-15$ dendrites.

a
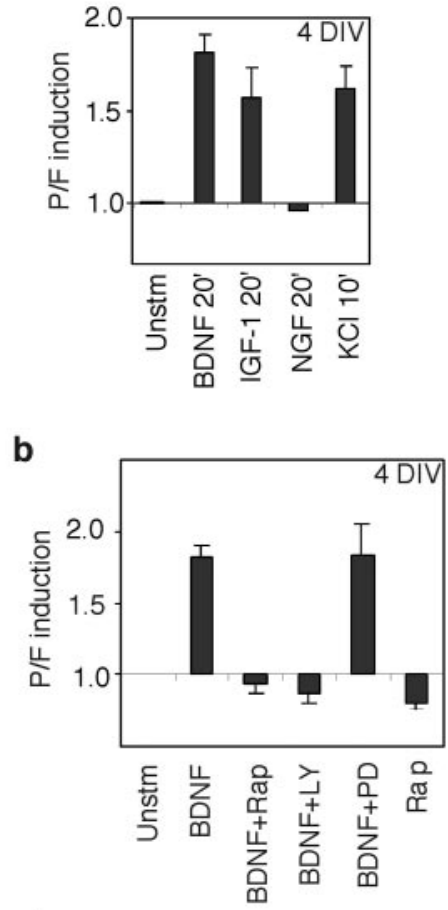

d

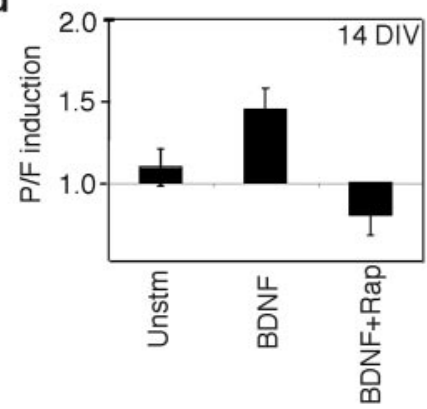

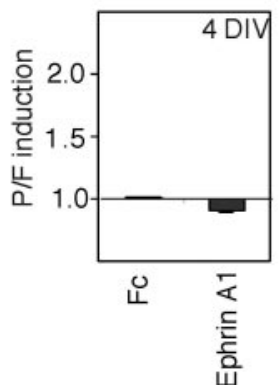

C

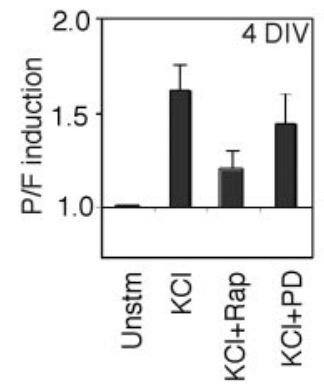

Figure 2. Multiple stimuli can regulate mRNA translation in neurons. $a$, Effect of growth factor treatment on the polysome profile. Neurons were treated with growth factors or stimulated with $60 \mathrm{~mm} \mathrm{KCl}$ for the indicated times and harvested as in Figure 1. b, PI3K-mTOR signaling is required for the BDNF-induced polysome shift. Neurons were starved, pretreated with actinomycin $\mathrm{D}$, and incubated with the indicated inhibitors for 20 min before BDNF stimulation. Cells were harvested $20 \mathrm{~min}$ after BDNF addition. Rap, Rapamycin $(20 \mathrm{ng} / \mathrm{mll}) ; \mathrm{LY}, 25$ $\mu \mathrm{M}$ LY294002; PD, 60 MM PD98059. c, Depolarization stimulates mRNA translation through distinct mechanisms. Neurons were starved, pretreated with actinomycin D, and incubated with inhibitors for $20 \mathrm{~min}$ before $60 \mathrm{~mm} \mathrm{KCl} \mathrm{stimulation.} \mathrm{Inhibitor} \mathrm{treatment} \mathrm{was} \mathrm{performed} \mathrm{as}$ described above. Error bars represent the SE of at least three independent experiments. $d$, BDNF induces a polysome shift in cortical neurons at 14 DIV. Neurons were treated as in $b$, polysome fractionation was performed, and the $P / F$ ratios were calculated. Error bars represent the $S E$ of three independent experiments.

To quantify the number of granules within individual dendrites, images were thresholded in NIH Image. Distal dendritic segments were highlighted based on MAP2 staining, and the analyze particles function of NIH Image was used. Only particles of a size larger than five pixels were taken into account.

RNA transfection of green fluorescent protein fusion transcripts. The luciferase coding region in pBluescript (pBSSK)-Luc (generous gift from J. Richter, University of Massachusetts Medical School, Worcester, MA) was replaced with eGFP, resulting in pBSSK-enhanced green fluorescent protein (eGFP). The full-length $3^{\prime}$ untranslated region (UTR) region for Homer2 was derived by PCR from a postnatal day 14 rat forebrain cDNA using the following primers: Homer2-UTR-fw: 5'-ATGCTCTAGAGAACGAATGTTTATTAAGCACCTA-3'; Homer2-UTR-bw: 5' - 
GTATCCATCGATCTAGGCACGGATAACTAGGG-3'. PCR products were verified by sequencing and cloned into pBSSK-eGFP downstream of the eGFP coding sequence using the $\mathrm{ClaI}$ and $\mathrm{Xba \textrm {I }}$ restriction sites. The pBSSK-eGFP-control construct contained the last nucleotides of the 3'UTR of CamKII $\alpha$, including a polyA signal, with cytoplasmic polyadenylation element sites mutated to prevent dendritic localization. In vitro transcription of eGFP-3'UTR fusion transcripts was performed on XbaIlinearized vectors using mMessage Machine Kit T7 (Ambion). Capped RNA was purified and transfected into 7 DIV hippocampal neurons using the Trans Messenger Reagent (Qiagen, Hilden, Germany) according to the manufacturer's protocol. Cells were processed for in situ hybridization and immunostaining $3 \mathrm{hr}$ after transfection.

\section{Results}

BDNF has recently been shown to stimulate mRNA translation in neurons (Takei et al., 2001). It has not been clear, however, whether BDNF induces translation globally or rather stimulates the translation of a specific subset of mRNAs.

To determine the effects of BDNF treatment on the translational profile of mRNA in neurons, cellular RNA and its associated ribosomal proteins were extracted from E18 cortical neurons cultured for $4 \mathrm{DIV}$ and fractionated on a conventional sucrose gradient. RNA was separated into peaks of increasing density (a polysome profile) (Fig. 1a) corresponding to messenger ribonucleoproteins (mRNPs), the $80 \mathrm{~S}$ ribosome $(\mathrm{F})$, and mRNAs associated with increasing numbers of actively translating ribosomes [polyribosomal fraction (P)]. Previous studies have demonstrated that increased mRNA translation results in a shift of mRNA and ribosomal subunits into the polysomal fractions (Hershey et al., 1996). To obtain a numerical representation of the distribution of messenger and ribosomal RNAs throughout the gradient, we calculated a $\mathrm{P} / \mathrm{F}$ ratio (see Materials and Methods). The addition of BDNF to cortical cultures caused a rapid increase in the calculated $\mathrm{P} / \mathrm{F}$ ratio (Fig. $1 b$ ), reflecting an increase in RNA in the polysomal fraction. This effect first became apparent $10 \mathrm{~min}$ after BDNF stimulation, peaked by 20 min, and was maintained for up to $60 \mathrm{~min}$ (Fig. 1b, left panel). The increase in $\mathrm{P} / \mathrm{F}$ ratio after exposure to $\mathrm{BDNF}$ was highly reproducible in $>30$ experiments.

Because the exposure of neurons to BDNF is known to induce gene transcription (Bonni and Greenberg, 1997), we considered whether the increase in polyribosome-associated mRNA in BDNF-treated neurons might reflect increased mRNA synthesis rather than increased translation of preexisting mRNAs. The pretreatment of neurons with the transcription inhibitor actinomycin D led to a decrease in the amount of RNA that we were able to isolate from neuronal cultures (Fig. 1b, left panel); however, the relative increase in the $\mathrm{P} / \mathrm{F}$ ratio observed after BDNF stimulation was not affected by actinomycin $\mathrm{D}$ pretreatment (Fig. $1 b$, right panel). This result indicates that although newly synthesized mRNA contributes to the pool of mRNAs within the polysome fraction to some extent, the increase in the amount of mRNA associated with polysomes in BDNF-treated neurons occurs even in the absence of BDNF-induced transcription. We conclude that the BDNF-induced increase in the P/F ratio is caused by BDNF stimulation of mRNA translation.

In addition to BDNF, IGF-I treatment or membrane depolarization by $\mathrm{KCl}$ induced a shift in the polysome profile similar to that observed after BDNF treatment of neurons (Fig. 2a). In contrast, treatment with aggregated ephrinA, which activates the EphA family of receptor tyrosine kinases, had no detectable effect on the polysome profile (Fig. $2 a$ ), despite the ability of the ephrinA to induce EphA receptor phosphorylation (data not shown). Furthermore, treatment with NGF, whose receptor TrkA is not
Table 1. Polysome-associated mRNAs in cortical neurons at 4 and 14 DIV as determined by microarray

\begin{tabular}{lll}
\hline & 4 DIV array & 14 DIV array \\
\hline Total genes & 8800 & 8800 \\
Expressed genes & 3527 & 3499 \\
BDNF induced & 162 & 143 \\
BDNF induced plus rapamycin sensitive & 79 & 48 \\
\hline
\end{tabular}

detectably expressed in cortical cultures at 4 DIV, did not significantly affect the observed P/F ratio. Thus, although several extracellular factors induce mRNA translation as assessed by polysome profiling, this effect appears to be restricted to a subset of neuronal stimuli.

We next asked whether the BDNF-induced increase in mRNAs associated with polysomes reflects an increase in translational initiation. Binding of BDNF to its receptor TrkB is known to activate the PI3K signaling pathway (Patapoutian and Reichardt, 2001), which can stimulate translation initiation through activation of the mammalian target of rapamycin [mTOR/FRAP (FKBP12-rapamycin associated protein)/RAFT1 (rapamycin and FKBP12 target 1)]. mTOR catalyzes the phosphorylation of both the 4E-BP family member 4E-BP1 and p $70^{\mathrm{S} 6 \mathrm{~K}}$, thereby stimulating translation of a subset of growth factor-regulated mRNAs (Gingras et al., 2001). Addition of the mTOR inhibitor rapamycin or the PI3K inhibitor LY249002 to neuronal cultures at 4 DIV completely eliminated the BDNFinduced shift in the polysome profile (Fig. $2 b$ ). In contrast, inhibition of the mitogen-activated protein kinase (MAPK) pathway by addition of the MAP kinase kinase 1/2 inhibitor PD98059 had no effect on the ability of BDNF or IGF-I (data not shown) to induce a shift of mRNA into the polysome fraction (Fig. 2b), although PD98059 did effectively inhibit MAPK-dependent cAMP response element-binding protein phosphorylation (data not shown).

Although BDNF and IGF-I treatment appears to stimulate protein synthesis via PI3K-mTOR signaling, the membrane depolarization-induced increase in protein synthesis was only partially blocked by treatment with rapamycin or PD98059 (Fig. $2 c$ ), indicating that different extracellular stimuli induce mRNA translation by at least somewhat distinct mechanisms.

In neurons grown in culture for $4 \mathrm{DIV}$, synapses have not yet formed, so that the BDNF-induced increase in mRNAs associated with polysomes most likely reflects an increase in mRNA translation within the cell body and early developing neurites. We were interested, however, in identifying mRNAs that are locally translated in the synaptodendritic compartment and therefore also investigated the effect of BDNF on translation in 14 DIV cortical neurons (Fig. 2d). These cultures have formed synapses, as judged by staining for the presynaptic marker synaptophysin (data not shown). BDNF treatment of 14 DIV cultures led to a shift of mRNA into polysome fractions similar to that observed at 4 DIV (Fig. $2 b$ ), and this shift was again completely blocked by rapamycin pretreatment. The observed increase in the $\mathrm{P} / \mathrm{F}$ ratio after BDNF treatment of cortical neurons at 14 DIV reflects a net increase in the area under the polysome peak of $9 \pm 3.9 \%$, indicating that BDNF treatment of these neurons does not lead to a massive increase in polysome-associated mRNAs. Our findings suggest that BDNF stimulates the translation of a subset of preexisting mRNAs in cortical neurons at 4 and 14 DIV. They further demonstrate an important contribution of the mTOR-PI3K pathway to BDNF-regulated translation in neurons.

We next used Affymetrix DNA microarrays to identify the 
Table 2. Subset of mRNAs at 14 DIV whose polysome association is induced by BDNF in a rapamycin-sensitive manner, using a 1.3-fold cut-off

\begin{tabular}{|c|c|c|c|c|c|c|c|c|}
\hline \multirow[b]{2}{*}{ Accession number } & \multirow[b]{2}{*}{ Gene } & \multicolumn{7}{|c|}{ Fold induction } \\
\hline & & Bdnf1 & Bdnf2 & Bdnf3 & Bdnf Avg & Rap1 & Rap2 & Rap Avg \\
\hline \multicolumn{9}{|c|}{ Genes with dendritic localization of mRNA } \\
\hline M16960 & $\begin{array}{l}\text { Calcium-calmodulin-dependent protein } \\
\text { kinase II }\end{array}$ & 3 & 3 & 4.2 & $3.5 \pm 0.6$ & 0.3 & 0.3 & $0.3 \pm 0.03$ \\
\hline S39221 & NMDA receptor (NR1) & 1.7 & 2 & 1.6 & $1.6 \pm 0.1$ & 0.5 & 0.3 & $0.4 \pm 0.16$ \\
\hline \multicolumn{9}{|c|}{ Genes with known function at synapses } \\
\hline AB007689 & Homer2 (Vesl-2) & 1.8 & 5 & 2.7 & $3.2 \pm 1.6$ & 0.1 & 0.5 & $0.3 \pm 0.31$ \\
\hline AF016387 & Retinoid $X$ receptor $\gamma$ & 1.9 & 9 & 1.7 & $4.3 \pm 4.2$ & 0.8 & 0.5 & $0.7 \pm 0.18$ \\
\hline AF061945 & NMDA receptor-like long variant (NR3) & 2.3 & 3 & 3.9 & $3.0 \pm 0.8$ & 0.1 & 0.1 & $0.11 \pm 0$ \\
\hline AF063890 & PYK2 (cell adhesion kinase- $\beta$ ) & 3.7 & 4 & 1.9 & $3.3 \pm 1.2$ & 0.3 & 0.5 & $0.4 \pm 0.15$ \\
\hline AF087696 & DLG2 & 2.5 & 1.6 & 2.4 & $2.2 \pm 0.5$ & 0.9 & 0.5 & $0.7 \pm 0.3$ \\
\hline AJ011115 & eNOS & 1.4 & 2.6 & 1.9 & $2.0 \pm 0.6$ & 0.6 & 0.1 & $0.3 \pm 0.33$ \\
\hline D31873 & LIMK-1 & 3.4 & 5.6 & 1.4 & $3.5 \pm 2.1$ & 0.8 & 0.7 & $0.7 \pm 0.05$ \\
\hline S80456 & Guanylate cyclase-A (GC-A) & 5.3 & 2 & 10 & $5.8 \pm 4.0$ & 0.4 & 0.9 & $0.6 \pm 0.37$ \\
\hline \multicolumn{9}{|l|}{ Other known genes } \\
\hline AF030091 & Ania-6 & 1.8 & 5 & 1.7 & $2.9 \pm 2.0$ & 0.8 & 0.8 & $0.8 \pm 0.03$ \\
\hline AF062740 & Pyruvate dehydrogenase phosphatase & 1.8 & 2 & 1.6 & $1.8 \pm 0.2$ & 0.6 & 1 & $0.8 \pm 0.29$ \\
\hline C07012 & Cyclophilin c & 3.6 & 7.2 & 5.3 & $5.4 \pm 1.8$ & 0 & 0.4 & $0.2 \pm 0.29$ \\
\hline D00698 & Insulin-like growth factor I & 1.4 & 3.2 & 2.9 & $2.5 \pm 1.0$ & 0.7 & 0.7 & $0.7 \pm 0.03$ \\
\hline D10693 & Histamine $N$-methyltransferase & 2.4 & 2 & 7.2 & $3.9 \pm 2.9$ & 0.4 & 0.5 & $0.5 \pm 0.06$ \\
\hline D13122 & ATPase inhibitor protein & 2.1 & 1.5 & 4 & $2.5 \pm 1.3$ & 0.9 & 0.3 & $0.6 \pm 0.43$ \\
\hline D38036 & TSH receptor & 2.4 & 1.7 & 5.6 & $3.2 \pm 2.1$ & 0.2 & 0.2 & $0.2 \pm 0.02$ \\
\hline D49980 & 8-oxo-dGTPase & 1.6 & 3.8 & 4.2 & $3.2 \pm 1.4$ & 0.4 & 0.7 & $0.6 \pm 0.26$ \\
\hline E04009 & CNP & 2.1 & 1.4 & 1.4 & $1.6 \pm 0.4$ & 0.3 & 0.7 & $0.5 \pm 0.26$ \\
\hline J04963 & Ecto-ATPase & 5.6 & 5.8 & 2.3 & $4.6 \pm 2.0$ & 0.7 & 0.7 & $0.7 \pm 0.01$ \\
\hline L11025 & T-cell receptor $\alpha$ chain & 5.6 & 4 & 3.2 & $4.3 \pm 1.2$ & 0.8 & 0.3 & $0.5 \pm 0.38$ \\
\hline L37965 & T-cell receptor $\alpha$ chain & 16 & 14 & 5.8 & $12 \pm 5.4$ & 0.5 & 0.8 & $0.7 \pm 0.22$ \\
\hline M23643 & Thyrotropin-releasing hormone & 6.1 & 12 & 1.3 & $6.4 \pm 5.2$ & 0.1 & 0.2 & $0.1 \pm 0.12$ \\
\hline M29317 & IFN- $\gamma$ & 1.9 & 1.4 & 7.5 & $3.6 \pm 3.4$ & 0.7 & 0.5 & $0.6 \pm 0.1$ \\
\hline M89646 & Ribosomal protein S24 & 1.4 & 2 & 1.3 & $1.6 \pm 0.4$ & 0.6 & 0.5 & $0.6 \pm 0.02$ \\
\hline S76404 & H,K-ATPase $\beta$-subunit & 3.7 & 3.3 & 1.5 & $2.8 \pm 1.2$ & 1 & 0.8 & $0.9 \pm 0.13$ \\
\hline U40064 & $\operatorname{PPAR} \delta$ & 9.8 & 6.9 & 1.9 & $6.2 \pm 4.0$ & 0.8 & 0.8 & $0.8 \pm 0.03$ \\
\hline U52948 & C9 precursor & 2 & 2.1 & 1.5 & $1.9 \pm 0.3$ & 0.6 & 0.8 & $0.7 \pm 0.11$ \\
\hline X00336 & IFN- $\alpha 1$ & 2.6 & 3.2 & 2 & $2.6 \pm 0.6$ & 0.8 & 1 & $0.9 \pm 0.15$ \\
\hline X13722 & LDL-receptor & 2.7 & 1.7 & 3.8 & $2.8 \pm 1.1$ & 0.4 & 0.6 & $0.5 \pm 0.15$ \\
\hline X55446 & Cytochrome P-450 & 2 & 1.5 & 1.7 & $1.7 \pm 0.3$ & 0.7 & 0.3 & $0.5 \pm 0.29$ \\
\hline$X 57133$ & HNF4 & 9.2 & 3 & 5 & $5.7 \pm 3.2$ & 0.3 & 0.3 & $0.3 \pm 0.02$ \\
\hline$\times 63574$ & G-protein-coupled receptor & 7.4 & 1.6 & 3.8 & $4.3 \pm 3.0$ & 0.6 & 0.3 & $0.5 \pm 0.27$ \\
\hline Y07704 & BEST5 & 1.5 & 1.7 & 6.1 & $3.1 \pm 2.6$ & 0.1 & 0.5 & $0.3 \pm 0.24$ \\
\hline X05472 & 2.4 kb repeat DNA & 1.5 & 1.4 & 1.9 & $1.6 \pm 0.2$ & 0.6 & 0.8 & $0.7 \pm 0.11$ \\
\hline S70804 & Clone p6.1 transcript & 4.4 & 2 & 2.5 & $3.0 \pm 1.3$ & 0.9 & 0.9 & $0.9 \pm 0.03$ \\
\hline \multicolumn{9}{|l|}{ Ests } \\
\hline rx00909 & Similar to hook homolog 1 & 5.1 & 6.8 & 1.5 & $4.5 \pm 2.7$ & 0.9 & 0.9 & $0.9 \pm 0.04$ \\
\hline rx00909 & Similar to hook homolog 1 & 1.7 & 1.8 & 1.4 & $1.6 \pm 0.2$ & 0.6 & 0.7 & $0.7 \pm 0.08$ \\
\hline rx02711 & Similar to DNAJ-like & 4.2 & 1.5 & 9.1 & $4.9 \pm 3.8$ & 0.1 & 0.1 & $0.1 \pm 0.02$ \\
\hline rC_AA800678 & Similar to TIP47 & 1.3 & 3.5 & 1.5 & $2.1 \pm 1.2$ & 0.9 & 1 & $0.9 \pm 0.07$ \\
\hline rC_AA859581 & Similar to $\lg 11$ & 4.6 & 2.5 & 10 & $5.8 \pm 4.0$ & 0.2 & 0.8 & $0.5 \pm 0.43$ \\
\hline rC_AA874877 & Similar to ring finger protein 10 & 11 & 1.7 & 2.3 & $4.8 \pm 5.0$ & 0.4 & 0.5 & $0.5 \pm 0.03$ \\
\hline rC_AA875255 & No similarity & 4.6 & 7 & 1.8 & $4.5 \pm 2.6$ & 0.5 & 0.1 & $0.3 \pm 0.27$ \\
\hline rC_AA891713 & Similar to ribosomal protein L13a & 1.7 & 1.5 & 1.3 & $1.4 \pm 0$ & 0.8 & 1 & $0.5 \pm 0.04$ \\
\hline rC_Al112237 & Similar to NADH dehydrogenase & 1.7 & 1.5 & 1.3 & $1.5 \pm 0.2$ & 0.8 & 1 & $0.9 \pm 0.15$ \\
\hline rC_Al172411 & Similar to glutathione peroxidase 3 & 1.3 & 1.4 & 1.4 & $1.4 \pm 0.1$ & 1 & 0.8 & $0.9 \pm 0.13$ \\
\hline rC_Al175486 & Similar to ribosomal protein S7 & 1.8 & 1.4 & 1.4 & $1.6 \pm 0.3$ & 0.4 & 0.7 & $0.5 \pm 0.24$ \\
\hline rC_AA875107 & Similar to ubiquinone oxidoreductase & 2.4 & 1.4 & 1.7 & $1.8 \pm 0.5$ & 0.7 & 0.9 & $0.8 \pm 0.12$ \\
\hline
\end{tabular}

mRNAs in italics are also induced by BDNF in 4 DIV cortical neurons. Rap, Rapamycin.

specific messages whose translation is induced by BDNF in an mTOR-dependent manner. The microarray analysis was performed using RNA isolated from the polysomal fractions of 4 or 14 DIV cortical neurons that were left untreated, exposed to BDNF for $20 \mathrm{~min}$, or exposed to BDNF for $20 \mathrm{~min}$ in the presence of rapamycin.

The results of the Affymetrix DNA array analysis are summarized in Table 1 . Of the 8800 genes present on the array, $\sim 3500$ $(40 \%)$ showed detectable hybridization to mRNAs that were present in the polysomal fractions obtained from both unstimu- lated and BDNF-treated neurons. Using a 1.3-fold cutoff, we found that BDNF reproducibly stimulated polysome association $(n=3)$ of 162 mRNAs in neurons at 4 DIV and 143 mRNAs at 14 DIV. So that we might focus our attention primarily on BDNFregulated mRNAs whose translation was affected at the level of translational initiation, we used the mTOR inhibitor rapamycin. Rapamycin effectively blocked BDNF-stimulated polysome association of 79 mRNAs at 4 DIV and 48 mRNAs at 14 DIV $(n=2)$. Thus, our microarray analysis indicates that BDNF treatment induces the translation of a relatively small subset of mRNAs in 


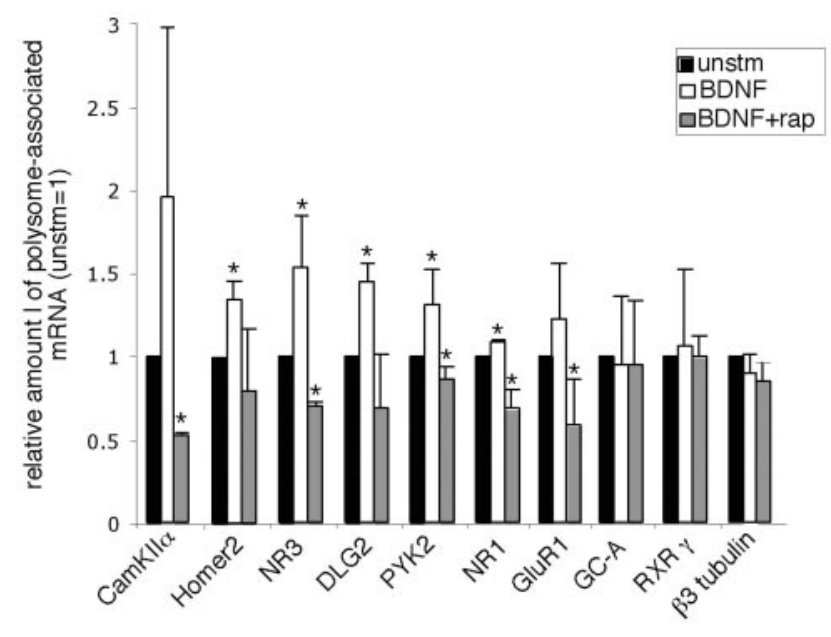

Figure 3. Association of specific neuronal mRNAs with polysomes after BDNF stimulation. Cultured E18 rat cortical neurons at 14 DIV were serum starved, preblocked with actinomycin D, and treated with or without BDNF for $20 \mathrm{~min}$. When indicated, $20 \mathrm{ng} / \mathrm{ml}$ rapamycin was added $20 \mathrm{~min}$ before BDNF stimulation (Rap + BDNF). After sucrose gradient separation and fractionation, $1 \mu \mathrm{g}$ of RNA from combined polysome fractions was purified and reverse transcribed to generate CDNA. Relative mRNA levels were determined using quantitative real-time PCR (unstimulated $=1$ ). Error bars represent the $\mathrm{SE}$ of three independent experiments. Asterisk indicates that the respective value is significantly different from unstimulated control $(p<0.05)$.

a
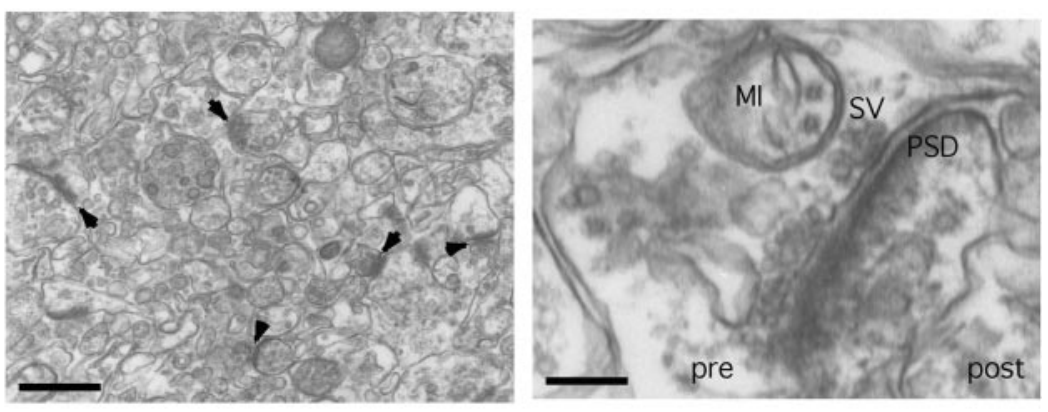

b

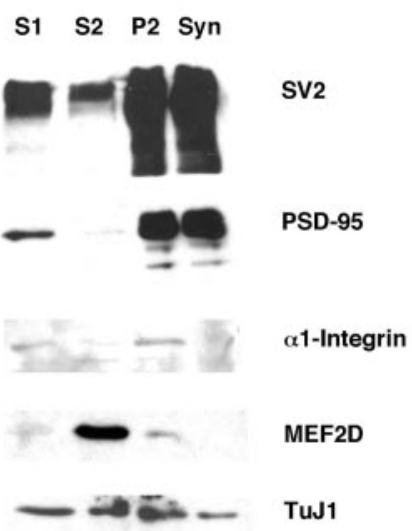

C

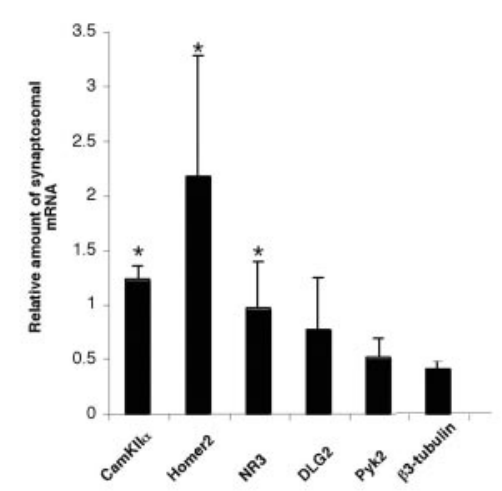

Figure 4. Homer2 mRNA is enriched in synaptoneurosomes. $a$, Electron micrographs of a representative synaptoneurosome preparation at low (bar $=500 \mathrm{~nm}$ ) and high (bar $=200 \mathrm{~nm}$ ) magnification. Arrowheads in the left panel point to juxtaposed presynaptic and postsynaptic membranes. The right panel shows an individual synaptoneurosome, with a presynaptic mitochondrion (MI), synaptic vesicles (SV), and the postsynaptic density (PSD). $b$, Enrichment of synaptic proteins in synaptoneurosomes. The synaptoneurosome preparation was performed as described in Materials and Methods, and samples were taken at each stage of the procedure. Aliquots (20 $\mu \mathrm{g}$ ) of each fraction were resolved by SDS-PAGE, and Western blotting was performed with antibodies to SV2, PSD95, $\alpha 1$-integrin, MEF2D, and TuJ1 as a loading control. The lanes are labeled as follows:S1, whole lysate before centrifugation; S2, supernatant from P2 spin; $P 2$, pellet from P2 spin $(14,000 \times g)$; Syn, synaptosomal fraction. c, Relative abundance of the indicated messages in synaptoneurosomes was determined by quantitative RT-PCR analysis. Values represent the ratio of the relative mRNA amount in synaptoneurosomes to the relative mRNA amount in total brain at P15. Error bars represent the SE of three independent experiments. Asterisk indicates that the respective value is significantly different from the $\beta 3$-tubulin control $(p<0.05)$. neurons, in agreement with results that we obtained from the quantification of polysome profiles (Figs. 1, 2). The 48 BDNFregulated mRNAs identified from cortical neurons at 14 DIV include the CamKII $\alpha$ and NMDA receptor subunit 1 (NR1) mRAs, two messages that have previously been shown to be localized to dendrites (Steward and Schuman, 2001). In addition, Ho rosine kinase 2 (PYK2), endothelial nitric oxide synthase ing $m$ RNAs might and/or dendrites. The complete list of 79 mRNAs identified in our screen using cortical neurons at 4 DIV can be found on-line (supplemental Table S1, available at www.jneurosci.org/cgi/ content/full/24/33/7366/DC1).

We next used quantitative RT-PCR analysis to validate the results of the microarray screen, focusing primarily on mRNAs that are known to encode proteins that have been implicated in syaptic function. In total, we analyzed nine candidate mRNAs, some association for seven of these messages (Fig. 3). No changes in polysome association were observed for the internal control mRNA $\beta 3$ tubulin. The BDNF-induced increase in the association of specific mRNAs with polysomes was not caused by an effect of BDNF on the overall abundance of these mRNAs, because the total level of expression of the mRNAs studied did not change significantly after BDNF addition (data not shown).

Our microarray and quantitative RTPCR results indicate that BDNF induces the translation of a number of mRNAs that encode proteins that function at synapses; however, the studies that we have described thus far do not address whether the translation of the identified mRNAs occurs locally within dendrites or axons. We used four distinct methods to determine whether any of the seven validated BDNFregulated mRNAs localized to dendrites and were translated within the dendritic compartment. These approaches include (1) determining whether the mRNA is enriched in synaptoneurosomes relative to whole brain extracts, (2) assessing whether the mRNA is detected in neuronal dendrites by in situ hybridization, (3) determining whether sequences within the mRNA can confer dendritic targeting to a heterologous mRNA, and (4) determining whether translation of the mRNA is enhanced by exposure of synaptoneurosomes to BDNF.

To determine the relative abundance of BDNF-regulated mRNAs in the synaptodendritic compartment, we prepared synaptoneurosomes from rat forebrain (see Materials and Methods). The quality of the synaptoneurosome preparation was assessed by electron microscopy and Western blotting. By electron microscopy we 
found that the synaptoneurosome preparation was composed of a large number of intact synaptoneurosomes (Fig. 4a) that contained a postsynaptic density (PSD), intact mitochondrion (MI), and well preserved presynaptic vesicles (SV). Using Western blotting, we found that the synaptoneurosome preparation was enriched in both presynaptic (SV2) and postsynaptic (PSD-95) proteins relative to whole-brain extract (Fig. 4b). In contrast, we were unable to detect the nonsynaptic plasma membrane protein $\alpha 1$-integrin and the nuclear protein MEF2D in the synaptoneurosome preparation. These findings indicate that the synaptoneurosome preparation is essentially uncontaminated by nonsynaptic plasma membrane and nuclear fractions and should be useful for the study of mRNA translation in the synaptodendritic compartment. Using quantitative RT-PCR, we found that the CamKII $\alpha$ and Homer2 mRNAs and, to a lesser extent, the NR3 mRNA were enriched in extracts from synaptoneurosomes compared with whole-brain extracts (Fig. 4c). In contrast, the DLG2 and PYK2 mRNAs, like the cell body-restricted $\beta 3$-tubulin mRNA, were not enriched in synaptoneurosomes relative to a whole-brain extract.

Based on these results, we concentrated on the Homer2 and CamKII $\alpha$ mRNAs in further studies. CamKII $\alpha$ serves as a positive control because CamKII $\alpha$ mRNA has previously been shown to be locally translated within dendrites in response to BDNF. Because we cannot rule out the possibility that our synaptoneurosome preparation is contaminated with nondendritic membranes, we used in situ hybridization of cultured hippocampal neurons as an independent approach to investigate whether the Homer2 mRNA is localized within dendrites (Fig. 5). Using this method, we found that Homer2 mRNA was localized to granules within neuronal processes that in some cases are visible as far as $100 \mu \mathrm{m}$ away from the cell body (Fig. $5 c$, top panel, $c^{\prime}$, high-power magnification of individual dendrites). Simultaneous immunofluorescence staining with an antibody that recognizes the dendritic marker protein MAP2 confirmed that these processes represented neuronal dendrites (Fig. $5 a-d$, bottom panel). The Homer2 mRNA staining pattern was strikingly similar to the in situ staining patterns of the CaMKII $\alpha$ and MAP2 mRNAs, two mRNAs that have previously been shown to be localized to dendrites (Fig. $5 a, a^{\prime}, b, b^{\prime}$ ). To establish the specificity of the in situ hybridization protocol, we examined the distribution of another neuronal mRNA, the Rho guanine nucleotide exchange factor (GEF) 11 mRNA (Fukuhara et al., 1999), and found the ArhGEF11 mRNA to be restricted mostly to the nuclear and perinuclear regions of the neurons (Fig. $5 d, d^{\prime}$ ). Statistical analysis of randomly chosen dendrites confirmed that the average signal intensity for the Homer 2 and CamKII $\alpha$ mRNAs was significantly higher than that for the ArhGEF11 mRNA along the entire length of the dendrite (Fig. $5 e$ ). Similarly, the number of mRNA granules detected in the distal region of individual dendrites was significantly higher for Homer2 and MAP2 as compared with the ArhGEF11 control (Fig. 5f). Taken together, these results provide evidence that the Homer2 mRNA, like the CaMKII $\alpha$ and MAP2 mRNAs, is localized in the dendritic compartment.

To obtain further evidence that the Homer2 mRNA is targeted specifically to dendrites, we asked whether this mRNA contains a defined dendritic targeting sequence. We concentrated on the $3^{\prime}$ UTR of the mRNA because sequence elements within the CamKII $\alpha 3^{\prime}$ UTR have been shown to mediate dendritic targeting of CamKII $\alpha$ in vivo (Mayford et al., 1996). The 3'UTR of Homer2 was fused to GFP and the resulting GFP-Homer2-3'UTR fusion mRNA was introduced into hippocampal neurons at $7 \mathrm{DIV}$, and the subcellular localization of the RNA was monitored by in situ hybridization with a probe directed against the GFP coding region. MAP2 immunohistochemistry was used to identify dendritic processes. GFP-Homer2-3'UTR RNA was readily detectable in neuronal cell bodies and dendrites (Fig. $6 a$ ). In contrast, a control RNA containing the GFP coding region and a polyadenylation signal of an unrelated mRNA (see Materials and Meth- 
a

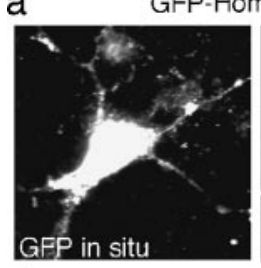

$a^{\prime}$

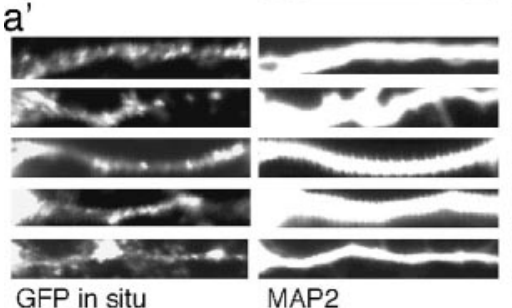

GFP in situ

C

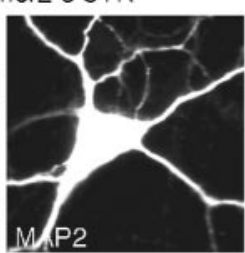

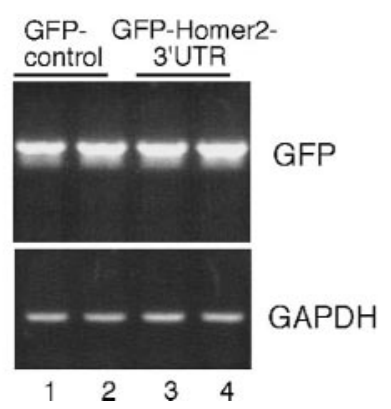

b

GFP in situ

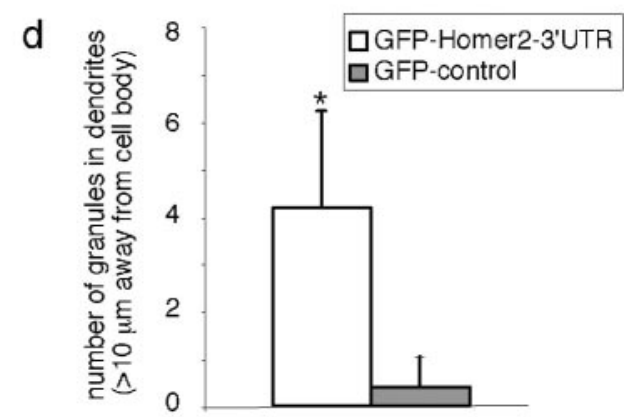

Figure 6. The $3^{\prime}$ UTR of Homer2 is sufficient for dendritic targeting. Hippocampal neurons at 7 DIV were transfected with GFP-Homer2-3' UTR and GFP-control RNA and processed for in situ hybridization with a probe specific for GFP ( $a, b$, left panel). Costaining for MAP2 protein was used to visualize dendrites ( $a, b$, right panel). Higher-magnification images illustrate the presence of RNA granules in multiple dendrites of GFP-Homer2-3'UTR-transfected neurons ( $a^{\prime}$, left panel) and their almost complete absence in GFP-control-transfected neurons ( $b^{\prime}$, right panel). Representative examples from one of three independent experiments are shown. Scale bar, $20 \mu \mathrm{m}$. c, Total RNA was prepared from GFP-control (lanes 1, 2) and GFP-Homer2-3' UTR (lanes 3, 4)-transfected neurons and used for semiquantitative RT-PCR analysis with primers specific for GFP (top panel) or GAPDH (bottom panel) as a loading control. $d$, The number of RNA granules in distal dendritic segments was determined for neurons transfected with the indicated RNAs. Values represent the mean of at least 12 dendrites for each construct. Asterisks indicate that the respective values are significantly higher than the value for the GFP-control construct $(p<0.05)$.

ods) was found almost exclusively in the cell body (Fig. $6 b$ ). Higher magnification of dendrites showed that GFP-Homer2$3^{\prime}$ UTR RNAs was present in large granules within dendrites, suggesting that this RNA is transported in the form of large mRNP complexes (Fig. $6 a^{\prime}$ ). Semiquantitative RT-PCR analysis confirmed that nearly equal amounts of the various GFP fusion transcripts are present in neurons after transfection (Fig. 6c). Quantification of the number of RNA granules found in distal dendritic segments demonstrated that dendrites of neurons transfected with the GFP-Homer2-3'UTR contained significantly more RNA granules than dendrites of neurons transfected with the GFP-control RNA (Fig. 6d). These findings, taken together with the analysis of the synaptoneurosome preparation (Fig. 4) and the in situ hybridization studies of endogenous Homer2 mRNA (Fig. 5), suggest that Homer2 mRNA is targeted into dendrites of cultured neurons and that sequences in the $3^{\prime}$ UTR of this mRNA are sufficient for the targeting event.

Our observation that the Homer2 mRNA is localized to dendrites (Figs. 5, 6) and that BDNF treatment leads to an increased association of Homer2 mRNA with polysomes (Fig. 3) suggests that this mRNA is likely locally translated in dendrites in response to BDNF. To obtain additional evidence that Homer2 mRNA is translated within the synaptodendritic compartment in response to BDNF treatment, we stimulated purified synaptoneurosomes with BDNF in the presence of $\left[{ }^{35} \mathrm{~S}\right]$ methionine to label newly synthesized proteins. The $\left[{ }^{35} \mathrm{~S}\right]$ methionine-labeled extracts were then prepared from the synaptoneurosomes, and the amount of Homer2 protein that was synthesized before and after BDNF treatment was quantified by immunoprecipitation (IP) with specific antibodies (Fig. 7). IP with an antibody specific for GluR1, a protein that was recently shown to be locally translated in dendrites (Ju et al., 2004), was used as a positive control. Quantification of the radiolabeled bands after IP (see insets) revealed that the addition of BDNF led to a significant increase in the synthesis of Homer2 (Fig. 7a) and GluR1 (Fig. 7b). In contrast, BDNF treatment did not significantly increase $\left[{ }^{35} \mathrm{~S}\right]$ methionine incorporation into total synaptoneurosome protein, indicating that BDNF does not lead to a global increase in translation (Fig. 7c). The lack of radiolabeled $\alpha 1$-integrin protein (a nonsynaptic protein) in anti-integrin antibody immunoprecipitates from synaptoneurosomes confirmed the specificity of the IP reactions (Fig. $7 d$ ). These findings suggest that BDNF stimulates the synthesis of Homer2 and GluR1 protein within synaptoneurosomes. Taken together with the finding that BDNF induces the movement of the Homer 2 mRNA to polysomes and our data that this mRNA is localized to dendrites, the ${ }^{35}$ S-labeling experiment provides evidence that the Homer2 mRNA is locally translated within dendrites.

We next investigated the mechanism by which BDNF regulates the translation of Homer2 and GluR1 mRNAs within dendrites. Our finding that the BDNF-induced shift in the association of mRNA with polysomes is blocked by rapamycin (Fig. $2 b$ ) indicates that BDNF induces mRNA translation in neurons by an mTOR-dependent mechanism, consistent with a previous report (Takei et al., 2001). It was not clear, however, whether the mTOR signaling pathway also regulated local translation of specific mRNAs in axons or dendrites. To determine whether the mTOR signalingpathway mediates BDNF induction of mRNA translation in dendrites, we first asked whether components of the mTOR signaling pathway are activated within dendrites after exposure to BDNF. For this purpose, we used antibodies that recognize the phosphorylatedactivated forms of $\mathrm{p} 70^{\mathrm{S} 6 \mathrm{~K}}$ or eIF- $4 \mathrm{E}$, two targets of the mTOR signaling pathway whose phosphorylation correlates with mRNA translational initiation (Fig. $8 a, b$ ). We found that BDNF treatment of cortical neurons leads to the phosphorylation of $\mathrm{p} 70^{56 \mathrm{~K}}$ and eIF-4E within $10 \mathrm{~min}$. Importantly, we were able to detect the phosphorylated-activated forms of p70 ${ }^{\mathrm{S} 6 \mathrm{~K}}$ and eIF-4E within dendrites of BDNF-treated neurons (Fig. $8 a^{\prime}, b^{\prime}$ ), suggesting that $\mathrm{BDNF}$ treatment induces the local phosphorylation of key components of the mRNA translational machinery within dendrites. Dendritic localization of components of the translation initiation machinery like eIF-4E is in agreement with the results from a previous report (Tang et al., 2002). In contrast, we could not 

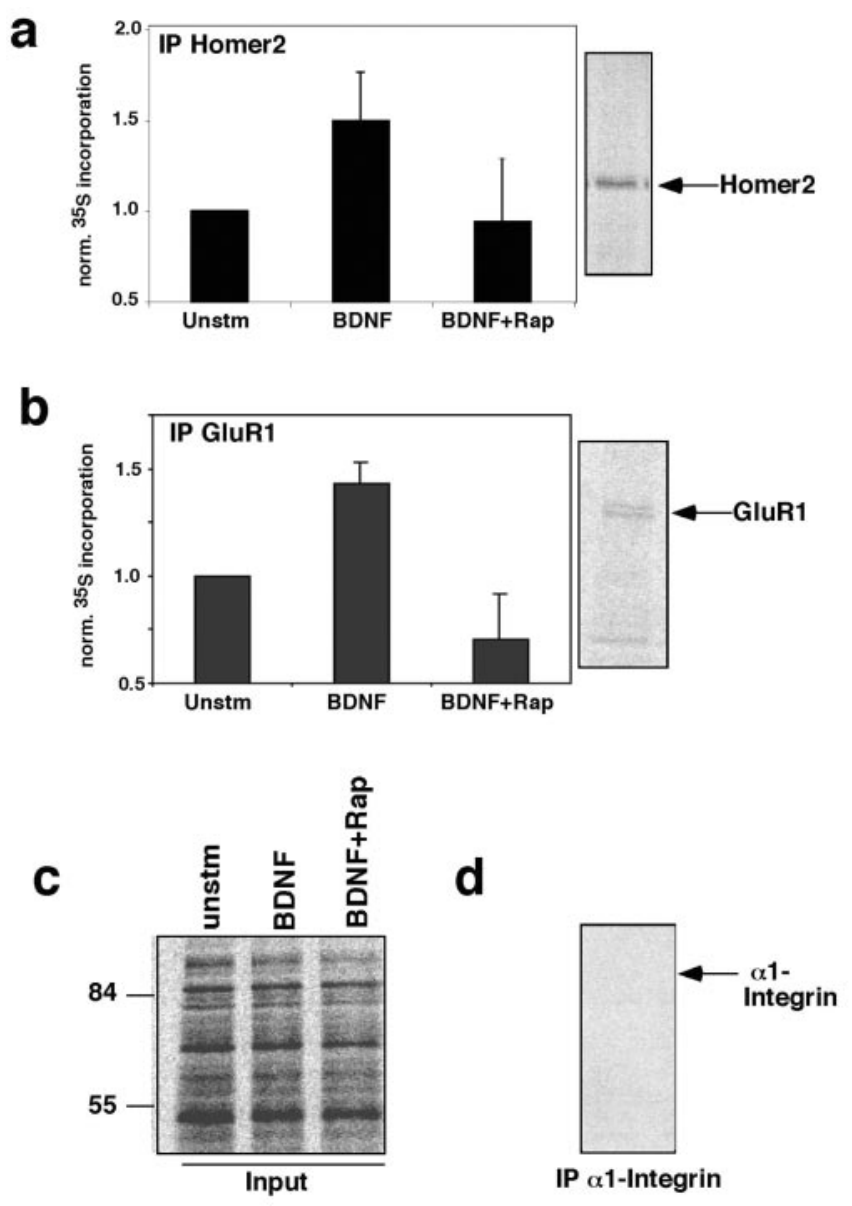

Figure 7. BDNF treatment increases the synthesis of Homer2 and GluR1 protein in synaptoneurosomes in a rapamycin-sensitive manner. Synaptoneurosomes were prepared as above, incubated at $37^{\circ} \mathrm{C}$, and stimulated with BDNF for 0 or 60 min in the presence of $100 \mu \mathrm{Ci} / \mathrm{ml}$ $\left[{ }^{35} \mathrm{~S}\right]$ methionine. The stimulation was performed in the presence or absence of rapamycin. Lysates were immunoprecipitated with antibodies to Homer2 ( $a)$, GluR1 (b), and $\alpha 1$-integrin $(d)$, resolved on SDS-PAGE gel, and visualized by autoradiography. Autoradiographs of lysates before immunoprecipitation are shown in c. The quantification of autoradiographs from three independent experiments is shown (unstimulated $=1$ ). ${ }^{35} \mathrm{~S}$ incorporation into Homer2 and GluR1 protein is significantly higher in BDNF-treated samples compared with unstimulated control samples $(p<0.05)$.

detect the phosphorylated form of $\mathrm{p} 70^{\mathrm{S} 6 \mathrm{~K}}$ in GFAP-positive glia cells present in our neuronal culture (supplemental Fig. S1, available at www.jneurosci.org/cgi/content/full/24/33/7366/DC1)). This finding suggests that BDNF enhancement of translation in cortical cultures is caused by a neuron-specific activation of translation factors.

To investigate further the role of the mTOR signaling pathway in BDNF-induced local phosphorylation of translation initiation factors, we examined the ability of BDNF to induce the phosphorylation of $\mathrm{p}^{7} 0^{\mathrm{S} 6 \mathrm{~K}}$ and $\mathrm{eIF}-4 \mathrm{E}$ within synaptoneurosomes in the presence or absence of rapamycin (Fig. 8c). When purified synaptoneurosomes were exposed for $10 \mathrm{~min}$ to BDNF alone, we found a significant increase in the phosphorylation of $\mathrm{p} 70^{\mathrm{S} 6 \mathrm{~K}}$ and eIF-4E. The BDNF-induced phosphorylation of $\mathrm{p} 70^{\mathrm{S} 6 \mathrm{~K}}$ and eIF-4E was partially inhibited when the synaptoneurosome preparation was preincubated with rapamycin. The observed inhibition was specific to mTOR signaling targets, because phosphorylation of the BDNF receptor TrkB was unaffected by rapamycin treatment. Taken together, these findings suggest that BDNF ac- tivates key components of the mRNA translation machinery within dendrites by an mTOR-dependent pathway.

To examine further the subcellular localization of activatedphosphorylated translation factors in neuronal processes, we performed immunocytochemistry on hippocampal neurons at 14 DIV (Fig. 9). In BDNF-treated cultures, phospho-Trk (a), phospho-eIF-4E $(d)$, and phospho-p70 ${ }^{\text {S6K }}(g)$ were found in a punctate pattern in neuronal dendrites, similar to their distribution in cortical neurons at 7 DIV (Fig. 8). Some of the puncta corresponded to synaptic regions, as revealed by double labeling with PSD-95 $(b, c, e, f)$ and synapsin $(h, i)$. A partial colocalization between phosphorylated translation factors and the synaptic marker proteins is clearly illustrated by insets at high magnification $(c, f, i)$. Our findings suggest that the local phosphorylation of Trk receptor and downstream components of the mTOR signaling pathway in response to BDNF is occurring in part in synaptic regions.

Finally, we were interested in whether the mTOR signaling pathway was important for the BDNF-induced local translation of the Homer2 and GluR1 mRNAs. Using ${ }^{35} \mathrm{~S}$ labeling of synaptoneurosomes (Fig. 7), we found that rapamycin completely inhibited the BDNF-mediated increase in ${ }^{35} \mathrm{~S}$ incorporation into Homer2 (Fig. 7a) and GluR1 (Fig. 7b) protein. This result indicates that local activation of components of the mTOR signaling pathway is required for the BDNF-evoked translation of dendritically localized mRNAs such as the Homer2 and GluR1 mRNA.

\section{Discussion}

Evidence suggests that BDNF regulation of local mRNA translation is an important mechanism by which BDNF may affect brain development and plasticity. So far, however, local translation in response to BDNF has been shown for only two mRNAs, CamKII $\alpha$ and Arc (Aakalu et al., 2001; Yin et al., 2002). It was not known whether exposure to BDNF induces the translation of a wide array or a select group of mRNAs, and it was unclear whether the translation of these mRNAs is restricted to the cell body or occurs locally in neuronal processes. We undertook a genome-wide microarray approach using RNA isolated from the polysomal fractions of neurons left unstimulated or exposed to BDNF to identify additional mRNAs whose translation is regulated by BDNF. Of nearly 3500 mRNAs that were expressed in the neurons at the time that synapses are forming, we found 48 mRNAs whose translation is induced after exposure to BDNF in a rapamycinsensitive manner. To assess the validity of our microarray screen, we studied in more detail BDNF regulation of the translation of several of the identified mRNAs. Using quantitative RT-PCR, we demonstrated that BDNF stimulation of neurons leads to an increased polysome association of seven of the nine mRNAs investigated: CamKII $\alpha$, GluR1, NR1/3, PYK2, Homer2, and DLG2. Taken together, these results indicate that using mRNA isolated from polysomal fractions to probe microarrays is a valid and useful way to identify mRNAs whose translation is induced by extracellular stimuli. Because we were able to confirm increased polysome association for seven of nine mRNAs tested, we propose that the translation of many of the $48 \mathrm{mR}$ NAs identified in our screen is likely to be induced by BDNF in neurons. It is intriguing that many of the mRNAs identified in the screen using cortical neurons at 14 DIV encode proteins that function at synapses, including NR1, NR3, Homer2, PYK2, DLG-2, and the previously identified CamKII $\alpha$ (Table 2 ), whereas many of the mRNAs identified at 4 DIV encode 
a
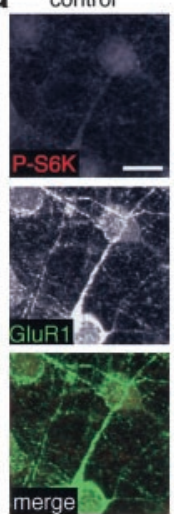

a'

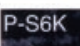

BDNF $10^{\prime}$

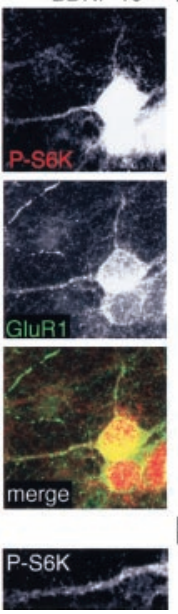

b control

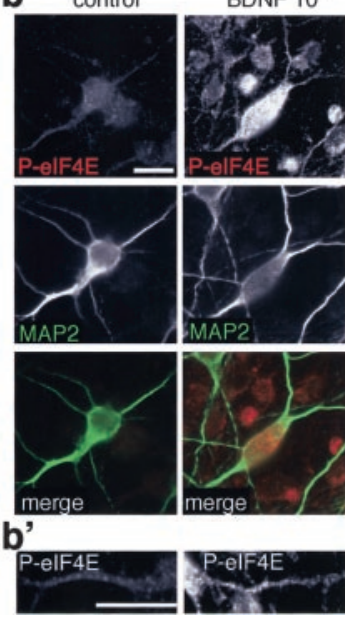

C

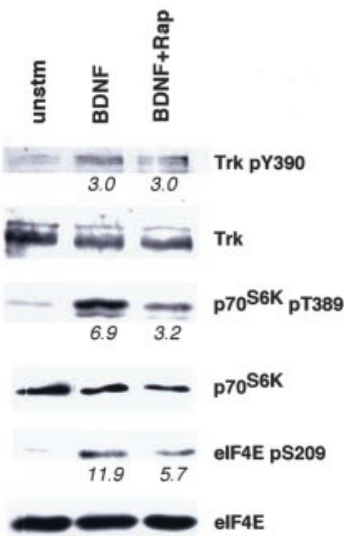

Figure 8. BDNF stimulation induces the local phosphorylation of multiple translation factors in neuronal dendrites in a rapamycin-sensitive manner. $a, b$, BDNF stimulation induces the local phosphorylation of translation factors in dendrites. E18 cortical neurons at 7 DIV were serum starved for 4 hr before stimulating with BDNF $(50 \mathrm{ng} / \mathrm{ml})$ for $10 \mathrm{~min}$. Samples were fixed and immunocytochemistry was performed with anti-phospho-p70 56K (Thr 389) (a) and anti-phospho-elF4E (Ser209) (b) together with anti GluR1 $(a)$ or anti-MAP2 $(b)$ to stain dendrites. Higher-magnification images $\left(a^{\prime}, b^{\prime}\right)$ illustrate the presence of phosphorylated translation factors in representative dendrites. Scale bar, $20 \mu \mathrm{m}$. c, BDNF-induced phosphorylation of translation factors in synaptoneurosomes is rapamycin sensitive. Synaptoneurosomes were treated with BDNF ( $100 \mathrm{ng} / \mathrm{ml}$ ) for 10 min, in the presence of rapamycin $(20 \mathrm{ng} / \mathrm{ml})$ when indicated. Synaptosomal lysates were prepared and analyzed for the phosphorylation of translation factors by Western blotting as described above. Induction of phosphorylated protein relative to the unstimulated control is given below each blot. Results are representative of three independent experiments.
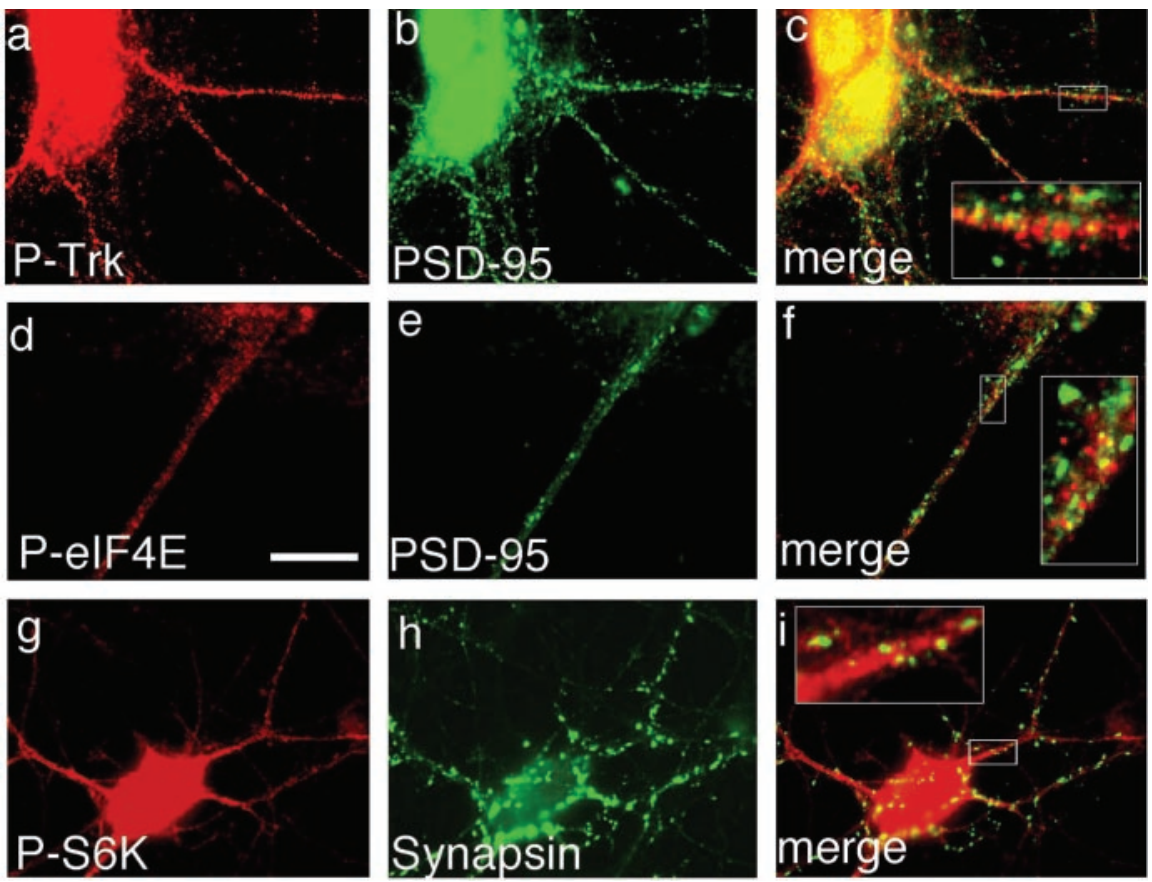

Figure 9. Local phosphorylation of translation factors near synapses. Hippocampal neurons (14 DIV) were stimulated as in Figure 8 before processing for immunocytochemistry with anti-phospho-Trk $(a, c)$, anti-phospho-elF4E $(d, f)$, and anti-phosphop70 ${ }^{56 \mathrm{~K}}(g, i)$ antibodies. Synaptic regions were visualized by costaining with anti-PSD-95 $(b, c, e, f)$ and anti-synapsin $(h, i)$ antibodies. Yellow signal in merged images indicates colocalization of phosphorylated proteins with synaptic marker proteins. Scale bar, $20 \mu \mathrm{m}$.

proteins with a known role in axon guidance, including MAP1B, G-protein-coupled receptor, and Limk1 (Meixner et al., 2000; Aizawa et al., 2001). Together, the identification of these mRNAs may provide clues regarding the mechanisms by which BDNF affects synaptic function and other processes

that involve mRNA translation such as axon guidance. Future work will address the functional consequences of BDNFregulated translation of specific mRNAs, especially those encoding synaptic proteins. In addition, we are currently investigating which of the mRNAs identified in our screen, in addition to the CamKII $\alpha$ and Homer2 mRNAs, are translated locally within axons and/or dendrites. Interestingly, we did not identify the Arc mRNA in our screen, although the translation of Arc was previously found to be induced by BDNF in synaptoneurosomes (Yin et al., 2002). Because of the neuronal culture conditions used in our study (serum starvation, transcriptional blockade), however, both dendritic and total levels of the activity-regulated Arc mRNA were very low (our unpublished observation). The failure to detect an increase in Arc mRNA association with polysomes by BDNF therefore may reflect the presence of very low levels of Arc mRNA at sites of translational activation.

Homer proteins are multimeric adaptors that cross-link mGluRs, IP3Rs, and Shank at the PSD (Xiao et al., 2000; Ehlers, 2002). Local translation of Homer2 in response to synaptic stimulation by BDNF therefore might lead to enhanced clustering of PSD components and, as a result, stabilization of the stimulated synapse. It is noteworthy that BDNF treatment also leads to the increased translation of the mRNA encoding for the Homerinteracting protein cortactin-binding protein 1 /Shank in 4 DIV cortical cultures (supplemental Table S1, available at www.jneurosci.org/cgi/content/full/24/ 33/7366/DC1). Interestingly, the constitutively expressed Homer2 protein regulates actin dynamics at synapses by binding actin and Rho family GTPases (Shiraishi et al., 1999). The ability of Homer to regulate the actin cytoskeleton may explain, at least in part, the observation that when overexpressed, Homer promotes the growth of dendritic spines (Sala et al., 2001). It is conceivable that the local translation of mRNAs that encode cytoskeletal regulators such as Homer may allow the remodeling of the actin cytoskeleton in dendrites and axons in response to extracellular stimulation, thereby promoting the formation and maintenance of synaptic connections.

The elucidation of the molecular mechanisms that control local translation of BDNF target mRNAs may provide insight into how BDNF regulates synaptic function. Using the specific kinase inhibitors rapamycin and LY, we found that BDNF-mediated activation of the $\mathrm{PI} 3 \mathrm{~K}-\mathrm{mTOR}$ signaling pathway is necessary for BDNF induction 
of translation of the Homer2 and GluR1 mRNAs in synaptoneurosomes. Although considered one of the most selective kinase inhibitors, rapamycin may affect neuronal translation by targeting proteins other than mTOR. In this regard, RNAi-mediated knock-down of mTOR might be an alternative way to selectively interfere with mTOR function in neurons. Together with previous reports demonstrating a requirement for PI3K and mTOR for the protein synthesis-dependent late phase of long-term potentiation (Raymond et al., 2002; Tang et al., 2002), our findings suggest that BDNF modulates synaptic function by activating the local translation of synaptic proteins via PI3K-mTOR signaling. Two recent studies reported an involvement of the MAP kinase pathway in BDNF-regulated translation (Takei et al., 2001; Kelleher et al., 2004). Based on these and our results, it will be important to determine the exact contribution of the mTOR and MAP kinase signaling pathway to BDNF-regulated translation at different stages of neuronal development. Because BDNF regulates a specific subset of mRNAs in neurons, it is likely that in addition to the general translation machinery, BDNF signaling targets sequence-specific trans-acting factors that are bound to regulatory regions of cognate mRNAs. Good candidates for such transacting factors are the neuronal RNA-binding proteins CPEB (cytoplasmic polydenylation element binding protein), ELAV (embryonic lethal abnormal vision)-like, and FMRP (fragile X mental retardation protein), which are known to regulate translation of dendritic mRNAs (Kiebler and DesGroseillers, 2000).

Work from a number of laboratories has provided tantalizing evidence for a role for local translational control in neuronal development and plasticity. Here we describe the first large-scale characterization of neuronal mRNAs that are translationally regulated in response to extracellular stimulation. These regulated transcripts encode a diverse group of proteins, including ion channels, kinases, cytoskeletal proteins, secreted factors, and proteins involved in metabolism. Our results suggest that some of these mRNAs may be translated locally in axons and/or dendrites. Although the role of the proteins encoded by these mRNAs in BDNF-induced plasticity remains to be determined, the diversity of mRNAs suggests a wide-ranging role for translational control in the neuronal response to BDNF.

\section{References}

Aakalu G, Smith WB, Nguyen N, Jiang C, Schuman EM (2001) Dynamic visualization of local protein synthesis in hippocampal neurons. Neuron 30:489-502.

Aizawa H, Wakatsuki S, Ishii A, Moriyama K, Sasaki Y, Ohashi K, SekineAizawa Y, Sehara-Fujisawa A, Mizuno K, Goshima Y, Yahara I (2001) Phosphorylation of cofilin by LIM-kinase is necessary for semaphorin 3A-induced growth cone collapse. Nat Neurosci 4:367-373.

Bonni A, Greenberg ME (1997) Neurotrophin regulation of gene expression. Can J Neurol Sci 24:272-283.

Brittis PA, Lu Q, Flanagan JG (2002) Axonal protein synthesis provides a mechanism for localized regulation at an intermediate target. Cell 110:223-235.

Campbell DS, Holt CE (2001) Chemotropic responses of retinal growth cones mediated by rapid local protein synthesis and degradation. Neuron 32:1013-1026.

Cohen-Cory S, Fraser SE (1995) Effects of brain-derived neurotrophic factor on optic axon branching and remodeling in vivo. Nature 378:192-196.

Ehlers MD (2002) Molecular morphogens for dendritic spines. Trends Neurosci 25:64-67.

Fukuhara S, Murga C, Zohar M, Igishi T, Gutkind JS (1999) A novel PDZ domain containing guanine nucleotide exchange factor links heterotrimeric G proteins to Rho. J Biol Chem 274:5868-5879.

Gingras AC, Raught B, Sonenberg N (2001) Regulation of translation initiation by FRAP/mTOR. Genes Dev 15:807-826.
Hershey JWB, Mathews MB, Sonenberg N (1996) Translational control. Plainville, NY: Cold Spring Harbor Laboratory.

Huber KM, Kayser MS, Bear MF (2000) Role for rapid dendritic protein synthesis in hippocampal mGluR-dependent long-term depression. Science 288:1254-1257.

Ju W, Morishita W, Tsui J, Gaietta G, Deerinck TJ, Adams SR, Garner CC, Tsien RY, Ellisman MH, Malenka RC (2004) Activity-dependent regulation of dendritic synthesis and trafficking of AMPA receptors. Nat Neurosci 7:244-253.

Kang H, Schuman EM (1996) A requirement for local protein synthesis in neurotrophin-induced hippocampal synaptic plasticity. Science 273:1402-1406.

Kelleher III RJ, Govindarajan A, Jung HY, Kang H, Tonegawa S (2004) Translational control by MAPK signaling in long-term synaptic plasticity and memory. Cell 116:467-479.

Kiebler MA, DesGroseillers L (2000) Molecular insights into mRNA transport and local translation in the mammalian nervous system. Neuron 25:19-28.

Korte M, Carroll P, Wolf E, Brem G, Thoenen H, Bonhoeffer T (1995) Hippocampal long-term potentiation is impaired in mice lacking brainderived neurotrophic factor. Proc Natl Acad Sci USA 92:8856-8860.

Mayford M, Baranes D, Podsypanina K, Kandel ER (1996) The 3'untranslated region of CaMKII alpha is a cis-acting signal for the localization and translation of mRNA in dendrites. Proc Natl Acad Sci USA 93:13250-13255.

McAllister AK, Lo DC, Katz LC (1995) Neurotrophins regulate dendritic growth in developing visual cortex. Neuron 15:791-803.

Meixner A, Haverkamp S, Wassle H, Fuhrer S, Thalhammer J, Kropf N, Bittner RE, Lassmann H, Wiche G, Propst F (2000) MAP1B is required for axon guidance and is involved in the development of the central and peripheral nervous system. J Cell Biol 151:1169-1178.

Ming GL, Wong ST, Henley J, Yuan XB, Song HJ, Spitzer NC, Poo MM (2002) Adaptation in the chemotactic guidance of nerve growth cones. Nature 417:411-418.

Ouyang Y, Rosenstein A, Kreiman G, Schuman EM, Kennedy MB (1999) Tetanic stimulation leads to increased accumulation of $\mathrm{Ca}(2+) /$ calmodulin-dependent protein kinase II via dendritic protein synthesis in hippocampal neurons. J Neurosci 19:7823-7833.

Patapoutian A, Reichardt LF (2001) Trk receptors: mediators of neurotrophin action. Curr Opin Neurobiol 11:272-280.

Rao A, Steward O (1991) Evidence that protein constituents of postsynaptic membrane specializations are locally synthesized: analysis of proteins synthesized within synaptosomes. J Neurosci 11:2881-2895.

Raught B, Gingras AC (1999) eIF4E activity is regulated at multiple levels. Int J Biochem Cell Biol 31:43-57.

Raymond CR, Redman SJ, Crouch MF (2002) The phosphoinositide 3-kinase and p70 S6 kinase regulate long-term potentiation in hippocampal neurons. Neuroscience 109:531-536.

Sala C, Piech V, Wilson NR, Passafaro M, Liu G, Sheng M (2001) Regulation of dendritic spine morphology and synaptic function by Shank and Homer. Neuron 31:115-130.

Scheetz AJ, Nairn AC, Constantine-Paton M (2000) NMDA receptormediated control of protein synthesis at developing synapses. Nat Neurosci 3:211-216.

Schuman EM (1999) Neurotrophin regulation of synaptic transmission. Curr Opin Neurobiol 9:105-109.

Shamah SM, Lin MZ, Goldberg JL, Estrach S, Sahin M, Hu L, Bazalakova M, Neve RL, Corfas G, Debant A, Greenberg ME (2001) EphA receptors regulate growth cone dynamics through the novel guanine nucleotide exchange factor ephexin. Cell 105:233-244.

Shiraishi Y, Mizutani A, Bito H, Fujisawa K, Narumiya S, Mikoshiba K, Furuichi T (1999) Cupidin, an isoform of Homer/Vesl, interacts with the actin cytoskeleton and activated rho family small GTPases and is expressed in developing mouse cerebellar granule cells. J Neurosci 19:8389-8400.

Steward O, Schuman EM (2001) Protein synthesis at synaptic sites on dendrites. Annu Rev Neurosci 24:299-325.

Steward O, Wallace CS, Lyford GL, Worley PF (1998) Synaptic activation causes the mRNA for the IEG Arc to localize selectively near activated postsynaptic sites on dendrites. Neuron 21:741-751.

Takei N, Kawamura M, Hara K, Yonezawa K, Nawa H (2001) Brain-derived neurotrophic factor enhances neuronal translation by activating multiple 
initiation processes: comparison with the effects of insulin. J Biol Chem 276:42818-42825.

Tang SJ, Reis G, Kang H, Gingras AC, Sonenberg N, Schuman EM (2002) A rapamycin-sensitive signaling pathway contributes to long-term synaptic plasticity in the hippocampus. Proc Natl Acad Sci USA 99:467-472.

van der Velden AW, Thomas AA (1999) The role of the 5' untranslated region of an mRNA in translation regulation during development. Int J Biochem Cell Biol 31:87-106.

Wu L, Wells D, Tay J, Mendis D, Abbott MA, Barnitt A, Quinlan E, Heynen A, Fallon JR, Richter JD (1998) CPEB-mediated cytoplasmic polyadenylation and the regulation of experience-dependent translation of alphaCaMKII mRNA at synapses. Neuron 21:1129-1139.

Xia Z, Dudek H, Miranti CK, Greenberg ME (1996) Calcium influx via the
NMDA receptor induces immediate early gene transcription by a MAP kinase/ERK-dependent mechanism. J Neurosci 16:5425-5436.

Xiao B, Tu JC, Worley PF (2000) Homer: a link between neural activity and glutamate receptor function. Curr Opin Neurobiol 10:370-374.

Yin Y, Edelman GM, Vanderklish PW (2002) The brain-derived neurotrophic factor enhances synthesis of Arc in synaptoneurosomes. Proc Natl Acad Sci USA 99:2368-2373.

Zhang HL, Eom T, Oleynikov Y, Shenoy SM, Liebelt DA, Dictenberg JB, Singer RH, Bassell GJ (2001) Neurotrophin-induced transport of a betaactin mRNP complex increases beta-actin levels and stimulates growth cone motility. Neuron 31:261-275.

Zhang X, Poo M (2002) Localized synaptic potentiation by BDNF requires local protein synthesis in the developing axon. Neuron 36:675-688. 